Environmental

Sciences and

Ecology: Current

Research (ESECR)

\author{
Volume 1 Issue 5, 2021 \\ Article Information \\ Received date: June 21, 2021 \\ Published date: July 09, 2021 \\ *Corresponding author \\ R Sikka, Department of Soil Science, \\ PAU, Ludhiana-141004, India \\ sikkar@pau.edu
}

Distributed under Creative Commons CC-BY 4.0

\section{Importance of Nano Fertilizers in}

\section{Sustainable Agriculture}

\author{
Chaitra P, Anu Kalia, Radha Ahuja, SPK Sidhu and R Sikka \\ Department of Soil Science, PAU, India
}

\section{Introduction}

The major constraints of current agriculture include shrinkage of farmland, imbalanced fertilizer application, low soil organic carbon and limited water resources. These agricultural practices adopted for ensuring enhanced food production have led to excess use of agrochemicals resulting in accelerated contamination of the soil, water and air resources. Therefore, the post green revolution era is now witnessing the consequences of indiscriminate use of chemical fertilizers with $\sim 60$ per cent of our agriculture lands suffering from heavy application of fertilizers. After the introduction of high yielding and fertilizer responsive varieties, application of conventional fertilizers played an important role in increasing food production and its quality (Chaudhary et al 2017) [1]. However, excess and improper use of these fertilizers has led to environmental pollution due to loss of nutrients primarily through leaching causing ground water pollution, surface run-off and contamination of open water bodies leading to eutrophication and photo-volatilization of the applied fertilizer. These non-target losses account for low nutrient use efficiency of commercial fertilizer, which has been reported to be 35 to 40 per cent for nitrogen, 18 to 20 per cent for phosphorus and 35 to 40 percent for potassium. There is a need for identification of a suitable alternative to conventional fertilizers with reduced harmful impacts on the environment. Hence, it is now necessary to shift from conventional cultivation to modern agricultural practices to minimize the nutrient loss and yield gap while meeting the target of sufficient production at constant rate. Here, nanotechnology may play an important role to overcome these problems via balanced application of nutrients as nano-fertilizers and offer wide opportunities to provide a feasible alternative for Agri and food processing (Kim et al 2018) [2].

Nano Fertilizers and Their Importance in Agriculture

Nanoparticles are particulate matter having size dimension of 1 and $100 \mathrm{~nm}$ in size in at least one dimension (Liu and Lal 2015). Nano-scale nutrients when applied as Nano fertilizers are expected to reduce the nutrient leaching and volatilization losses, as this formulation may allow selective release linked with time and environmental conditions and may synchronize the release of nutrients with the uptake by crop. Further, nano-nutrient fertilizers exhibit high sorption capacity, surface area and control release of nutrients to targeted sites, hence these can be considered as smart nutrient delivery system (Rameshaiah et al 2015) [3]. Therefore, these nutrient formulations may act as possible alternatives to conventional fertilizers ensuring slow and control release of nutrients. Nanofertilizers increase the nutrient use efficiency, provide better yield and may help in reducing the soil pollution due to over-application of fertilizers (Naderi and Danesh-Sharaki 2013)[4]. These fertilizer formulations are anticipated to improve the crop growth and development due to its greater absorbance, high reactivity and ability to directly enter the cell through cell wall pores. Different types of Nanofertilizers can be produced by using different carrier materials e.g., hydroxyapatite nanoparticles, zeolite, mesoporous silica nanoparticles, nitrogen, copper, zinc, silica, carbon, and polymeric nanoparticles.

\section{Disadvantages of Nanofertilizers}

Human exposure to Nanofertilizers can lead to serious health risk due to associated cyto- and genotoxicity aspects. Nanoparticles can trespass the cell membrane(s) to reach cytoplasm, organelles and even cell nucleus can alter the gene expression in animals because of their size. Nanoparticles can enter the food chain and their increased dispersal in non-targeted species can induce adverse environmental impacts. These form of matter may affect the living organisms in many ways, particularly carbon-based nanoparticles can modify the DNA structure and the gene expression in plant tissues (Lahiani et al 2015) [5]. Zinc oxide nanoparticles have been observed to disturb the symbiotic relationship of rhizobia-legumes thereby affecting the nitrogen fixation process (Huang et al 2014) [6]. Iron based nanofertilizers can alter the hydraulic conductivity of roots due to the accumulation of the applied nanoparticles on the root surface, which leads to lowering of water and nutrient (such as $K, C_{a}$, $\mathrm{M}_{\mathrm{g}}$ and S) uptake.

\section{Conclusion}

In the current scenario, excess use of conventional fertilizers has polluted the soil, water and food. It is necessary to increase the agriculture productivity; meanwhile we should consider the damage caused by the new approaches. Nanotechnology is playing important role in agriculture sector, as use of Nano fertilizers can help to decrease the amount of fertilizers through the smart delivery of active ingredients; increased nutrient uptake and nutrient use efficiency, and decrease fertilizer losses through volatilization, leaching and runoff. Foliar application of Nano fertilizer is preferred over the soil application due to significant enhancement of growth, yield, quality, physiological and biochemical traits. It is not possible to generalize the efficacy of Nano fertilizers. Therefore, research is required to study the effects of Nano fertilizers under different climatic and soil conditions for their judicious use before marketing or distribution at the commercial scale. 


\section{References}

1. Chaudhary S, Dheri GS, Brar BS (2017) Long-term effects of NPK fertilizers and organic manures on carbon stabilization and management index under rice-wheat cropping system. Soil Tillage Res 166: 59-66.

2. Kim D Y, Kadam A, Shinde S, Saratale RG, Patra J, et al. (2018) Recent development in nanotechnology transforming the agricultural sector : a transition replete with opportunities. J Sci Food Agric 98: 849-64.

3. Rameshaiah G N, Pallavi J, Shabnam S (2015) Nano fertilizers and nano sensors an attempt for developing smart agriculture. Int J Eng Res Gen Sci 3: 314 20 .
4. Naderi MR, Danesh-Sharaki A (2013) Nanofertilizers and their role in sustainable agriculture. Int J Agri Crop Sci 19: 2229-2232.

5. Lahiani MH, Chen J, Irin F, Puretzky AA, Green MJ, et al. (2015) Interaction of carbon nanohorns with plants: Uptake and biological effects. Carbon 81: 607-619.

6. Huang YC, Fan R, Grusak MA, Sherrier JD, Huang CP (2014) Effects of nano$\mathrm{Zn}_{\mathrm{o}}$ on the agronomically relevant Rhizobiumelegume symbiosis. Sci Total Environ 497: 78-90. 